\title{
Effect of targeted silencing of IL-8 on in vitro migration and invasion of SKOV3 ovarian cancer cells
}

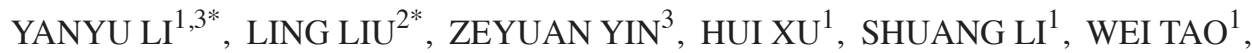 \\ HUI CHENG ${ }^{1}$, LEI DU ${ }^{4}$, XUEYUAN ZHOU ${ }^{4}$ and BEI ZHANG ${ }^{1,3}$ \\ Departments of ${ }^{1}$ Gynaecology and Obstetrics, and ${ }^{2}$ Pharmacology, Xuzhou Central Hospital, Xuzhou, \\ Jiangsu 221009; ${ }^{3}$ Xuzhou Clinical School and ${ }^{4}$ Jiangsu Key Laboratory of New Drug Research \\ and Clinical Pharmacy, Xuzhou Medical College, Xuzhou, Jiangsu 221000, P.R. China
}

Received February 1, 2016; Accepted May 13, 2016

DOI: $10.3892 / 01.2016 .5511$

\begin{abstract}
The aim of the study was to determine whether interleukin-8 (IL-8) affects human SKOV3 ovarian cancer cell migration and invasion by targeting silencing of IL-8 expression. Silencing small-interfering RNA (siRNA) targeting $I L-8$ gene was constructed to infect SKOV3 cells by lentiviral vector. The expression of IL-8 and p-nuclear factor (NF)- $\mathrm{\kappa B}$ protein was detected by western blot analysis. The wound scratch and Transwell tests were used to assay the cell migration and invasiveness of SKOV3 cells infected with lentiviral vector targeting $I L-8$ gene siRNA. The levels of IL-8 protein expressed by SKOV3 cells infected by lentiviral vector targeting $I L-8$ gene siRNA decreased by $72.3 \%$. IL- 8 $(50 \mathrm{ng} / \mathrm{ml})$ increased the ability of SKOV3 cells to suppress cell migration $(\mathrm{p}<0.01)$. Cisplatin and silencing of IL-8 achieved the ability to inhibit SKOV3 cell invasion $(\mathrm{p}<0.01)$, and $100 \mathrm{ng} / \mathrm{ml}$ concentration of IL-8 enhanced the ability of SKOV3 invasion $(\mathrm{p}<0.01)$. Silencing of IL-8 to a certain extent reduced the expression of $\mathrm{p}-\mathrm{NF}-\mathrm{\kappa B}$ proteins, but it was not statistically significant. In conclusion, silencing of IL-8 may inhibit the migration and invasion of SKOV3 cells, which may be independent of the $\mathrm{p}-\mathrm{NF}-\mathrm{\kappa B}$ protein.
\end{abstract}

\section{Introduction}

Ovarian cancer is a common malignant tumor of the female reproductive system $(1,2)$. As the majority of patients with ovarian cancer have insidious onset and methods of early diagnosis are lacking, $70 \%$ of patients are at an advanced stage

Correspondence to: Dr Bei Zhang, Department of Gynaecology and Obstetrics, Xuzhou Central Hospital, 199 Jiefang South Road, Xuzhou, Jiangsu 221009, P.R. China

E-mail: bettyzhang10@163.com

${ }^{*}$ Contributed equally

Key words: ovarian cancer, interleukin-8, cell migration, cell invasion, $\mathrm{p}$-nuclear factor- $\mathrm{\kappa} \mathrm{B}$ when the tumor is identified (FIGO stage III or IV) and the 5 -year survival rate is approximately $40 \%$ (3). The mortality rate ranks first in gynecologic malignant tumors (4), and it is extremely difficult to treat this disease.

Ovarian cancer has the characteristic that pelvic cavity spreads extensively, and metastasis of cancer cells is multifactorial and includes multiple steps. Interleukin-8 (IL-8) is a CXC inflammatory chemokine that is highly expressed in tumor microenvironment and has the functions of promoting migration and tumor cell growth (5). IL-8 is consistently highly expressed in patients with ovarian cancer and the ascitic fluid level of IL-8 is obviously higher than serum (6), suggesting that as an inflammatory chemokine, IL-8 is involved in the occurrence and development of ovarian cancer.

Experiments conducted in the present study aimed to exclude interference of endogenous IL-8 through lentiviral transfection technology, to observe its impact on invasion and migration of ovarian carcinoma cells and explore preliminarily its possible molecular mechanism to provide experimental basis for molecular target therapy for ovarian carcinoma.

\section{Materials and methods}

Materials. Ovarian carcinoma SKOV3 cell lines were obtained from the Shanghai Institute of Cell Library (Shanghai, China). The small interfering RNA (siRNA) was designed and constructed as a vector (plasmid without vector and bacterial strain containing this plasmid were all produced and identified by Nanjing Moji Biological Technology Development Co. Ltd., Nanjing, China). The main reagents used were: CCK-8, IL-8, RPMI-1640 basal culture medium, double-antibody and fetal bovine serum (FBS) (both from Gibco, Grand Island, NY, USA), acrylamide, methylene acrylamide, Tris-base, ammonium peroxydisulfate, TEMED, glycine and SDS (all from Biosharp, Hefei, China). The PVDF membrane, and chemiluminescent liquid were purchased from Thermo Fisher Scientific, Inc. (Waltham, MA, USA).

Methods. siRNA and siNC were confirmed as effective target sites by verifying the effective sequence from three sequences, and it was designed as shRNA. pLV2-shSIRT1 and pLV2-scramble vectors were constructed (Fig. 1). Cells 
infected with nonsense sequences were the scramble group. Non-infected cells served as the control group.

Plasmid was extracted by collecting $50 \mu \mathrm{l}$ of fresh bacteria fluid to inoculate with $30 \mathrm{ml} \mathrm{LB}$ culture medium (containing moderate antibiotics), followed by shock culturing for $16 \mathrm{~h}$ at $37^{\circ} \mathrm{C}$. The culture was centrifuged at $5,000 \times \mathrm{g}$ for $10 \mathrm{~min}$, at $25^{\circ} \mathrm{C}$, to collect the thallus and absorb supernatant as much as possible.

Buffer A1 (2.5 ml) was added and transferpettor positive displacement pipette (Sigma-Aldrich, St. Louis, MO, USA) was used to ensure that sedimentation of bacteria was resuspended. Subsequently, $2.5 \mathrm{ml}$ buffer B1 was used and reversed gently 10 times to mix evenly and allowed to stand for $5 \mathrm{~min}$ until the solution was viscous and clear. Subsequently, $1 \mathrm{ml}$ buffer N3 was added, and mixed immediately 5 times, followed by vigorous agitation 5 times, until white flocculent precipitate appeared. The lysate was transferred to high-speed centrifuge at $12,000 \mathrm{x} \mathrm{g}$ for $10 \mathrm{~min}$ at room temperature. Then, $5 \mathrm{ml}$ of 1 volume of buffer RET (Biosharp) was added to $3 \mathrm{ml}$ of $100 \%$ ethanol lysate and was agitated vigorously 5 times to mix evenly. The DNA column was centrifuged immediately and $6 \mathrm{ml}$ lysate was transferred to a DNA column with a collecting pipe immediately and centrifuged at 5,000 $\mathrm{x}$ g for $2 \mathrm{~min}$ at room temperature. The filtrate collected in the pipe was discarded and column was placed back in collecting pipe, this step was repeated until the appropriate solution passed through the DNA column. Five milliliters of $70 \%$ ethanol was added into the centrifugal column and centrifuged at $5,000 \mathrm{x} \mathrm{g}$ for $1 \mathrm{~min}$ at room temperature. The filtrate collected in the pipe was discarded and the column was placed back in the collecting pipe, a step that was repeated once again. The centrifugal column was placed back in the high-speed centrifuge at 5,000 x g for $10 \mathrm{~min}$ at room temperature with open cover to remove residual ethanol.

The centrifugal column was placed in a new 15-ml centrifuge tube. Endo-free elution buffer (Biosharp) was added in middle of the DNA column membrane and kept for $10 \mathrm{~min}$ at room temperature. The column was centrifuged again at $5,000 \times \mathrm{g}$ for $5 \mathrm{~min}$ to elute plasmid DNA. The eluent of the $15-\mathrm{ml}$ centrifuge tube was placed in the column, to elute for $1 \mathrm{~min}$, and centrifuged at 5,000 x $\mathrm{g}$ for $5 \mathrm{~min}$.

Virus transfection. Target cells $\left(1-2 \times 10^{5}\right)$ were inoculated in a 6-well plate for one day prior to lentiviral transfection. The medication treatment was given after 4 days. One milliliter of virus supernatant (removed at $-80^{\circ} \mathrm{C}$ in advance and melted on ice) was added to the wells, and mixed gently. Then, 6-8 $\mu 1$ polybrene, and cell state were added and observed after returning the cell plate to the incubator for 6- to 8-h incubation, and $1 \mathrm{ml}$ fresh culture medium was added. After infecting for $24 \mathrm{~h}$, fresh culture medium was added. Puromycin (final concentration was $5 \mu \mathrm{g} / \mathrm{ml}$ ) was added into the wells and infected for 2 days to screen infected SKOV3 cells, followed by replacement with new culture medium. After 1 week of culturing, positive cells were obtained.

Scratching test. A marker was used to draw horizontal lines under the 6-well plate uniformly, and a line approximately every 0.5 to $1 \mathrm{~cm}$ and across wells. Each well was crossed by at least 5 lines. Approximately $5 \times 10^{5}$ cells were added in the

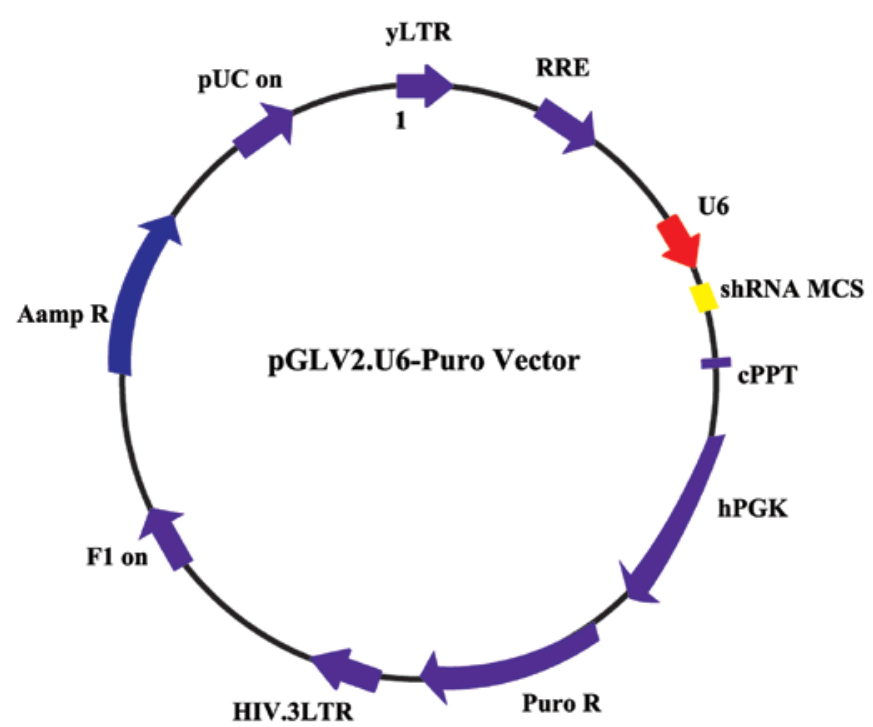

Figure 1. pLV2-shSIRT1 and pLV2-scramble vectors.

well, and a specific number was different from cell to cell, by average overnight. On the second day, a spearhead was used on the straight edge, which was perpendicular to the scratched lines. Phosphate-buffered saline (PBS) was used to wash the cells three times, and the cells that had been drawn were removed and placed back into serum-free medium. The cells were then incubated at $37^{\circ} \mathrm{C}$, in a $5 \% \mathrm{CO}_{2}$ incubator, and a sample was taken at $0,4,24$ and $48 \mathrm{~h}$ to capture images.

Transwell invasion test. The chambers were placed onto the cultured board. Preheated serum-free medium (300 $\mu \mathrm{l})$ was added in the upper chamber and allowed to stand for 15-30 min at $25^{\circ} \mathrm{C}$. Subsequently, the inoculum was aspirated. After completion of digestion, the inoculum was centrifuged and removed, the PBS was used twice to wash, and serum-free medium containing BSA was used for resuspension. The cell density was adjusted to $3 \times 10^{5}$. The cells were inoculated by adding $200 \mu \mathrm{l}$ of cell suspension to Transwell chamber. Then, $500 \mu \mathrm{l}$ of culture medium containing FBS was added to the lower chamber of a 24-well plate and cultured for $14 \mathrm{~h}$. After $0.1 \%$ crystal violet staining, the cells were observed using a microscope (SZ61; Olympus, Tokyo, Japan), images were captured and five horizons were randomly selected to count the cell numbers.

Western blot analysis and antibodies. Western blot analysis was used to detect the expression of IL- 8 and $\mathrm{p}-\mathrm{NF}-\kappa \mathrm{B}$ protein. When confluence of the number of growing cells reached $>80 \%$, the culture medium was removed. The prechilled PBS was used to wash the cells followed by radioimmunoprecipitation assay (RIPA). The cells were homogenized in RIPA buffer and subsequently centrifuged to extract total protein. The extracted protein was preserved at $-20^{\circ} \mathrm{C}$.

Western blotting was performed as previously reported (7). The primary rabbit polyclonal IL-8 antibody (dilution, 1:500; cat. no. ab7747; Abcam, Cambridge, MA, USA) was added to the membrane for incubation at $4^{\circ} \mathrm{C}$ for $12 \mathrm{~h}$. After incubation, the membrane was repeatedly washed in $0.2 \%$ TBST and incubated with secondary goat anti-rabbit (HRP) IgG antibody (dilution, 1:2,000; cat. no. ab6721; Abcam) at $25^{\circ} \mathrm{C}$. Images of 

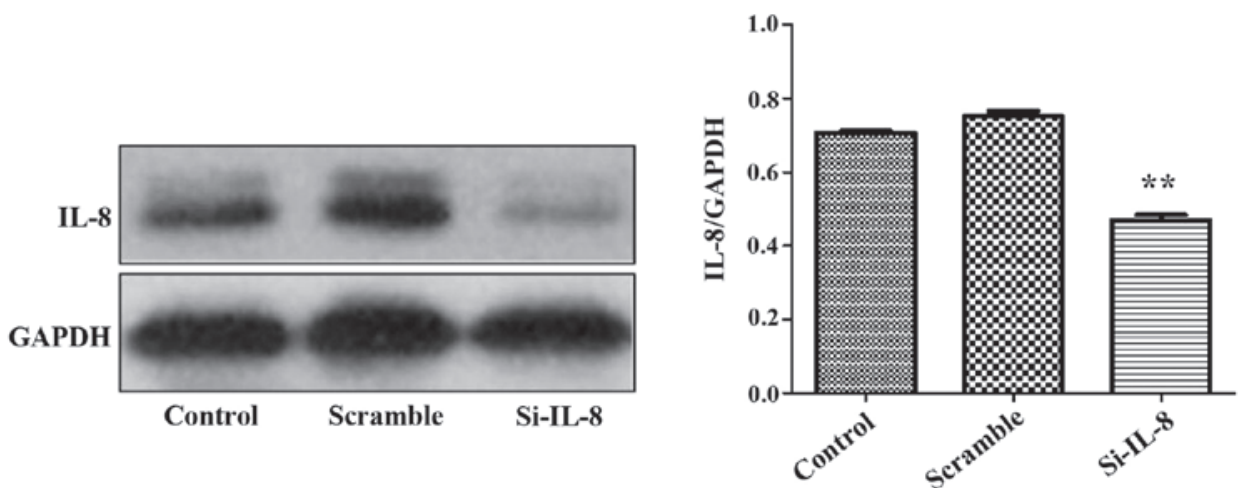

Figure 2. Impact of SKOV3 cell lines on the expression of IL-8 after lentiviral transfection. IL-8, interleukin-8. ${ }^{* *} \mathrm{P}<0.05$.
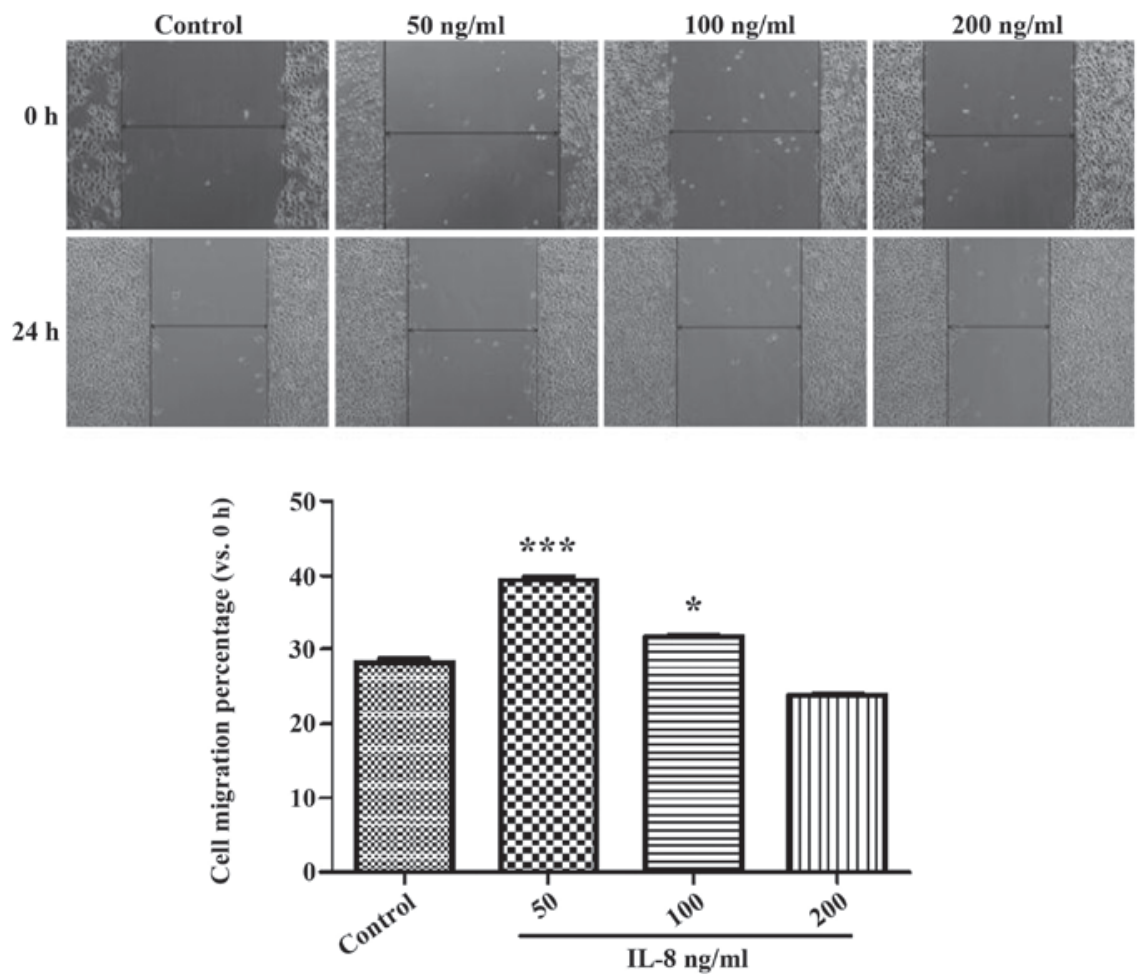

Figure 3. Impact of IL-8 at different concentrations on migration of SKOV3. IL-8, interleukin-8. ${ }^{*} \mathrm{P}<0.001$ and ${ }^{* * *} \mathrm{P}<0.05$.

separated proteins were captured after chemiluminescence reaction, and Gel-Pro gel Analyzer software (Silver Spring, MD, USA) was used to detect brand intensity. GAPDH was used as the internal control for normalization.

Statistical analysis. SPSS 19.0 software (IBM, Armonk, NY, USA) was used for statistical analysis. All quantitative data were expressed as means \pm standard deviation. Comparison between groups was done using one-way ANOVA test followed by post hoc test (Least Significant Difference). $\mathrm{P}<0.05$ indicated statistically significant results.

\section{Results}

Impact of SKOV3 cells on the expression of IL-8 after lentiviral transfection. It was found that in comparison to the control and nonsense sequence groups (scramble group), the
IL-8 expression level of SKOV3 cells in the si-IL-8 group decreased following the tranfection of si-IL-8 pLV2-shSIRT1, and its interference rate was $72.3 \%(\mathrm{p}<0.01)$ (Fig. 2).

Impact of different concentrations of IL-8 on the migration of SKOV3. The result of the experiment of CCK determined the concentration of IL-8, which was set at $50 \mathrm{ng} / \mathrm{ml}$ as a low-dose group, at $100 \mathrm{ng} / \mathrm{ml}$ as a medium-dose group and at $200 \mathrm{ng} / \mathrm{ml}$ as a high-dose group. Fig. 3 shows the width of the cell scratch in the IL- 8 medium- and high-dose groups was significantly higher than that of the control group $(\mathrm{p}<0.05)$, and the $50 \mathrm{ng} / \mathrm{ml}$ group showed more obvious effects $(\mathrm{p}<0.05)$. These results indicated that certain concentrations of echogenic IL-8 can promote SKOV3 cell migration.

Impact of IL-8 on the invasion of SKOV3 cells. Fig. 4 shows that cisplatin and IL- 8 silencing inhibited the invasion ability 

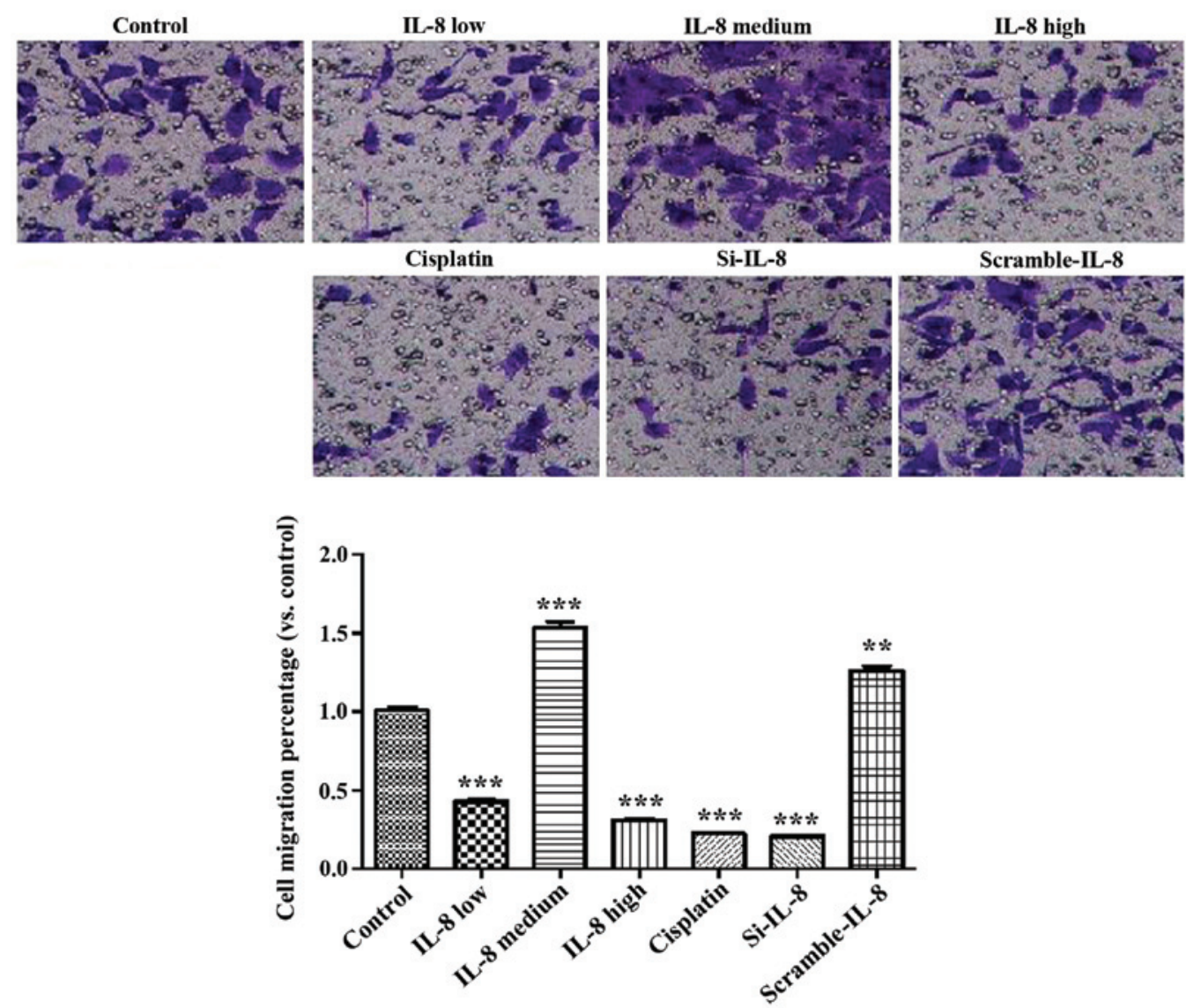

Figure 4. Impact of IL-8 on invasion of SKOV3 cells. IL-8, interleukin-8. ${ }^{* *} \mathrm{P}<0.01$, compared with control; ${ }^{* * * *} \mathrm{P}<0.001$, compared with control..
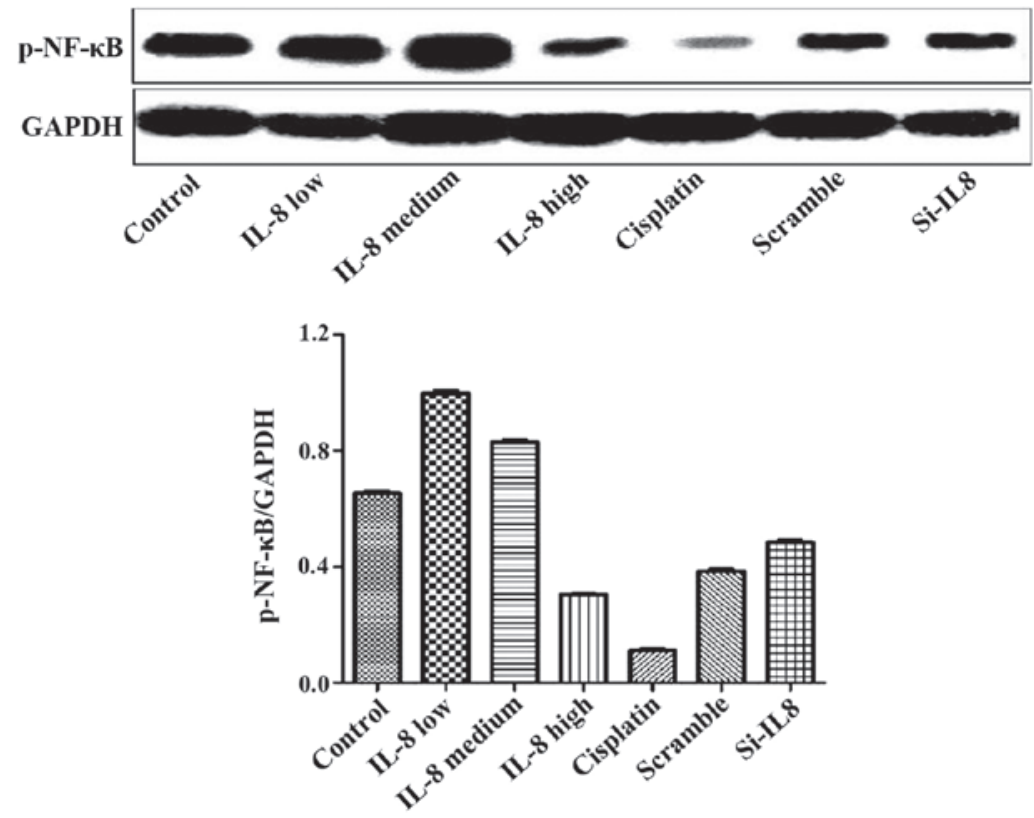

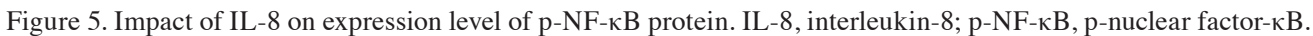

of SKOV3 ( $<<0.01$ ), and $100 \mathrm{ng} / \mathrm{ml}$ IL-8 enhanced the invasion ability of SKOV3 $(\mathrm{p}<0.01)$.

Detection of the expression of $p-N F-\kappa B$ protein in each group. The experimental results are shown in Fig. 5. Cisplatin and
IL-8 silencing decreased the expression of $\mathrm{p}-\mathrm{NF}-\mathrm{\kappa B}$ protein to some extent, and $100 \mathrm{ng} / \mathrm{ml} \mathrm{IL}-8$ strengthened the expression of $\mathrm{p}-\mathrm{NF}-\mathrm{\kappa B}$ protein. However, there was no statistical difference, suggesting that silencing of IL-8 and the expression of $\mathrm{p}-\mathrm{NF}-\mathrm{kB}$ protein may not be linked. 


\section{Discussion}

Ovarian cancer is a common female malignant tumor. Since ovary is in the deep pelvic cavity and early lesions are not easy to identify, most patients present at an advanced stage of disease. Applications of ideal cytoreductive surgery and chemotherapy regimens which are mainly platinum, have improved the treatment effects of ovarian cancer obviously, albeit the 5-year survival rate is only $30-40 \%$ (8) and the mortality rate ranks first in gynecologic tumors. The main reason is that $70 \%$ of patients are at an advanced stage at diagnosis, and $70 \%$ of patients have recurrence after treatment (8).

Therefore, research on better diagnosis and therapeutic approaches is crucial for ovarian cancer. With the rapid development of tumor immunology, biological treatment on tumor may be an important supplement to surgery, chemotherapy, radiotherapy and other traditional treatment methods (9). Use of biological treatment plays an increasingly important role in controlling tiny remnant tumors, delaying recurrence, increasing survival time, improving life quality and other aspects. It is an antitumor therapy that has developed rapidly during recent decade. Immunotherapy mainly constitutes cytokines and its antitumor effect has been highly valued. Thus, identifying target points of cytokines in the proliferation and metastasis of ovarian cancer is crucial to develop traditional treatments and improve the patient survival rate.

Cisplatin is a metal fluor-complex of platinum and can bind to DNA, leading to crosslinks of double strands of DNA, thereby inhibiting cell mitosis and proliferation. It is a cell cycle non-specific agent that can be applied to chemotherapy of various types of tumors and acts as a first-line chemotherapeutic agent to treat ovarian cancer (10). Appropriate concentrations were screened through the cell scratch test and mobility through screening at different time points. Results were selected at 0 and $24 \mathrm{~h}$ to exclude the impact of duration of cisplatin on this experiment.

It was found that TNF- $\alpha$, IL- 6 , IL-8 and other cytokines and chemotactic factors produced by inflammatory corpuscle within the tumor microenvironment promote cell growth, inhibit mutant cell apoptosis and play important roles in the growth and metastasis of malignant tumors (11). According to lentiviral transfection, targeting silent lentivirus infected and constructed silent SKVO3 cell lines of IL-8, avoiding the influence of endogenous IL-8. At the same time, we included a blank control group, low-dose, medium-dose, and high-dose IL-8 groups, cisplatin group, IL-8 silence group and nonsense sequence group. Results of the Transwell invasion experiment showed that the cisplatin group and IL-8-silenced group were able to inhibit tumor cell invasion, and $100 \mathrm{ng} / \mathrm{ml} \mathrm{IL-8}$ enhanced the invasion ability of cells, both of which suggested that IL-8 produced by tumor cells plays an important role in the cell invasion progress.

Inflammation is a pathophysiologic reaction that concerns inflammatory cells and inflammatory cytokines. Previous findings have shown that inflammation plays an important role in the occurrence and development of tumors and the mechanism of inflammation inducing tumors may contain two main aspects (12). First, inflammatory cells of tumor microenvironment produce reactive oxygen species (ROS) and reactive nitrogen cluster (NOS) which cause damage of cellular DNA. Secondly, cytokines and chemotactic and other factors released by inflammation cells enhance the signal of cell proliferation, promote rapid proliferation and cell differentiation in order to inhibit cell apoptosis (12).

Tumor-associated inflammation concerns the transcription factor nuclear factor pathway (13). NF- $\mathrm{kB}$ engages in the differentiation, proliferation and activation of immunological cells, and in the growth control of some cells, has the function of anti-apoptosis and plays a central role in the activation process of many pro-inflammatory cytokines (14). Expression of IL-8 is mainly regulated by activator protein-1 (AP-1) and $\mathrm{NF}-\mathrm{\kappa B}$, and it needs to combine with the G protein-coupled receptors, CXCR1 and CXCR2, to conduct biological effects. Previous findings have shown that a high expression of the content of IL-8 in a variety of malignant tumor tissues, such as melanoma, gastroenteric tumor, cancerous goiter, ovarian cancer, and lung carcinoma, was closely assoicated with the angiogenesis, growth, metastasis, recurrence of tumors (15). Furthermore, the serum level of IL-8 of patients with ovarian cancer prior to surgery was higher than that in healthy individuals. As the autocrine growth factor of tumor cells, IL-8 induces its own proliferation and promotes tumor growth (16).

Signal channel of inducing cancer cells to secrete IL-8 is complex. Inflammatory factors such as TNF-d and LPS can pass the NF- $\mathrm{KB}$ signal channel and induce the expression of IL-8 (17). In addition, the MAPK signaling channel is closely associated with IL-8, and after changes of the p38MAPK, ERK1/2 phosphorylation level, the signaling channels may have the ability of promoting the migration of tumor cells by regulating the stability of IL-8 mRNA (18).

Cisplatin and silencing of IL-8 decreased the expression of p-NF- $\mathrm{kB}$ protein while $100 \mathrm{ng} / \mathrm{ml} \mathrm{IL-8} \mathrm{enhanced} \mathrm{the} \mathrm{expres-}$ sion of p-NF- $\mathrm{kB}$ protein (19). Thus, IL-8 and cisplatin may inhibit the migration and proliferation of SKOV3 ovarian cancer cells by activating the NF- $\kappa \mathrm{B}$ channel.

Multigenes and multiprocedures are involved in development of malignant tumors, including ovarian cancer (20). Malignant tumor cells, especially ovarian cancer which are difficult to detect, diffuse rapidly at an advanced stage, while prognosis is delayed.

Thus, identification of appropriate therapeutic targets is crucial in the latest evolution in the treatment of ovarian cancer. Previous studies have reported the impact of IL-8 on the migration and invasion of tumor cells (21). However, those studies neglected that SKOV3 cells themselves can produce IL-8 thus impacting cell migration and invasion.

In the present study, the impact that the cells themselves produced through lentiviral transfection technology was not considered while it was verified that IL-8 has the function of promoting the migration of ovarian cells. The study emphasizes the role of IL- 8 by suggesting that antibacterial therapy plays an important role in complex treatments of ovarian cancer. From a standpoint of controlling the metastasis of ovarian cancer, the study provided new insight into treatments of ovarian cancer. At the same time, IL- 8 can be regarded as the key providing a new approach for controlling the invasion and migration of ovarian cancer. 


\section{References}

1. Kim H, Wu R, Cho KR, Thomas DG, Gossner G, Liu JR, Giordano TJ, Shedden KA, Misek DE and Lubman DM: Comparative proteomic analysis of low stage and high stage endometrioid ovarian adenocarcinomas. Proteomics Clin Appl 2: 571-584, 2008.

2. Siegel R, Naishadham D and Jemal A: Cancer statistics, 2012. CA Cancer J Clin 62: 10-29, 2012.

3. Jemal A, Bray F, Center MM, Ferlay J, Ward E and Forman D: Global cancer statistics. CA Cancer J Clin 61: 69-90, 2011.

4. Chen WQ, Zhang SW, Zou XN and Zhao P: Cancer incidence and mortality in China, 2006. Chin J Cancer Res 23: 3-9, 2011

5. Watanabe H, Iwase M, Ohashi M and Nagumo M: Role of interleukin-8 secreted from human oral squamous cell carcinoma cell lines. Oral Oncol 38: 670-679, 2002.

6. Barshishat M, Ariel A, Cahalon L, Chowers Y, Lider O and Schwartz B: TNFalpha and IL-8 regulate the expression and function of CD44 variant proteins in human colon carcinoma cells. Clin Exp Metastasis 19: 327-337, 2002.

7. Lee LF, Hellendall RP, Wang Y, Haskill JS, Mukaida N, Matsushima K and Ting JP: IL-8 reduced tumorigenicity of human ovarian cancer in vivo due to neutrophil infiltration. J Immunol 164: 2769-2775, 2000.

8. Jemal A, Siegel R, Ward E, Murray T, Xu J and Thun MJ: Cancer statistics, 2007. CA Cancer J Clin 57: 43-66, 2007.

9. Ozols RF: Update on the management of ovarian cancer. Cancer J 8 (Suppl 1): S22-S30, 2002.

10. Armstrong DK, Bundy B, Wenzel L, Huang HQ, BaergenR, Lele S, Copeland LJ, Walker JL and Burger RA; Gynecologic Oncology Group: Intraperitoneal cisplatin and paclitaxel in ovarian cancer. N Engl J Med 354: 34-43, 2006.

11. Lu H, Ouyang W and Huang C: Inflammation, a key event in cancer development. Mol Cancer Res 4: 221-233, 2006.

12. Li QQ, Chen ZQ, Cao XX, Xu JD, Xu JW, Chen YY, Wang WJ, Chen Q, Tang F, Liu XP, et al: Involvement of NF- $\mathrm{B}$ / miR-448 regulatory feedback loop in chemotherapy-induced epithelial-mesenchymal transition of breast cancer cells. Cell Death Differ 18: 16-25, 2011.
13. Bromberg $\mathbf{J}$ and Wang TC: Inflammation and cancer: IL-6 and STAT3 complete the link. Cancer Cell 15: 79-80, 2009.

14. Bartels M, Schweda AT, Dreikhausen U, Frank R, Resch K, Beil W and Nourbakhsh M: Peptide-mediated disruption of NFkappaB/NRF interaction inhibits IL- 8 gene activation by IL-1 or Helicobacter pylori. J Immunol 179: 7605-7613, 2007.

15. Subramaniam D, Ramalingam S, May R, Dieckgraefe BK, Berg DE, Pothoulakis C, Houchen CW, Wang TC and Anant S: Gastrin-mediated interleukin-8 and cyclooxygenase-2 gene expression: differential transcriptional and posttranscriptional mechanisms. Gastroenterology 134: 1070-1082, 2008.

16. Lee JW, Wang P, Kattah MG, Youssef S, Steinman L, DeFea K and Straus DS: Differential regulation of chemokines by IL-17 in colonic epithelial cells. J Immunol 181: 6536-6545, 2008.

17. Estrada Y, Dong J and Ossowski L: Positive crosstalk between ERK and p38 in melanoma stimulates migration and in vivo proliferation. Pigment Cell Melanoma Res 22: 66-76, 2009.

18. Padda RS, Gkouvatsos K, Guido M, Mui J, Vali H and Pantopoulos K: A high-fat diet modulates iron metabolism but does not promote liver fibrosis in hemochromatotic $\mathrm{Hjv}^{-1-}$ mice. Am J Physiol Gastrointest Liver Physiol 308: G251-G261, 2015.

19. Mabuchi S, Ohmichi M, Nishio Y, Hayasaka T, Kimura A, Ohta T, Saito M, Kawagoe J, Takahashi K, Yada-Hashimoto N, et al: Inhibition of NFkappaB increases the efficacy of cisplatin in in vitro and in vivo ovarian cancer models. J Biol Chem 279: 23477-23485, 2004.

20. Jones RG and Thompson CB: Tumor suppressors and cell metabolism: A recipe for cancer growth. Genes Dev 23: 537-548, 2009.

21. Shi J and Wei PK: Low-dose interleukin-8 induces the adhesion, migration and invasion of the gastric cancer SGC-7901 cell line. Oncol Lett 10: 2871-2877, 2015. 